\title{
Short and Long Term Effects of Pomegranate (Punica Granatum) Extracts on Apoptosis in Rat Kidney Induced by Diethylnitrosamine and Phenobarbital
}

\author{
Asmaa F. Hamouda and Nadia Z. Shaban \\ Biochemistry Departement, Faculty of Science, Alexandria University, Alexandria 21111, Egypt
}

\begin{abstract}
Pomegranate (Punica granatum L.) has strong anti-inflammatory, antioxidant, anti obesity, and anticancer effects. The effect of different pomegranate extracts, PE (peel extract), SOE (seed oil extract), and PJ (pomegranate juice) extract on levels of kidney caspase-3, DNAF (DNA fragmentation) and kidney function tests in rats treated and untreated with DEN (diethyl nitrosamine) and PB (Phenobarbital) during short (35 days) and long (154 days) period was studied. Injected of rats with DEN and PB caused an increased in the levels of DNAF, caspase-3 and kidney function tests, compared to the control in both period of study. Treatment of rats with PE, SOE, PJ pre, during, and post DEN and PB administration improved kidney function and decreased the levels of DNAF, and caspase-3 activities compared to the DEN group in both period of study, indicates that PE, SOE, PJ reduced and treatment apoptosis induced by DEN and PB. Treatment of healthy rats with PE, SOE, and PJ only for 35 days not increased kidney function or induced apoptosis for kidney tissues. Treatment with PJ alone in healthy kidney induced apoptosis which was higher than that induced by SOE and PE in case of long period study, this mean that fresh fruit or pomegranate juice safe for healthy in general at harvesting season only.
\end{abstract}

Key words: Kidney, apoptosis, diethylnitrosamine, phenobarbital, DNA fragmentation, pomegranate.

\section{Introduction}

Apoptosis is a general mechanism by which toxicants such as DEN can mediate a wide range of pathological organ responses, inflammation, and agenesis to tumour formation $[1,2]$. DEN (Diethylnitrosamine) is a well known potent carcinogenic agent present in tobacco smoke, water, processed food, agricultural chemicals and pharmaceutical products $[3,4]$. N-nitrosamines have been suggested to cause oxidative stress cell death due to involvement of free radicals which play an important role in the pathogenesis of kidney diseases [5]. PB (Phenobarbital), a derivative of barbituric acid, one of the classic AEDs (antiepileptic drugs), has recently become less popular due to its adverse effects, especially cognitive and behavioural side-effects [6]. Scientist reported that, $\mathrm{PB}$ is a nongenotoxic

Corresponding author: Asmaa F. Hamouda, PhD., research field: biochemistry. Email: asmaakingdom1@yahoo.com. hepatocarcinogen, and its administration at a high dose $(500$ ppm) after DEN injection promotes hepatocarcinogenesis in a rat model $[7,8]$.

Strategies to delay the onset of dialysis or to attenuate uremia often rely on dietary supplements [9]. Pomegranate is one of the oldest known drugs [10-12]. Pomegranate fruit presents strong anti-inflammatory, antioxidant, anticholesterol, antitumoral and pro-apoptotic activities [13-16].

Beneficial effects of pomegranate fruit due to the presence of ellagic acid, ellagitannins, punicic acid and other fatty acids, flavonoids, anthocyanidins, anthocyanins, estrogenic flavonols, and flavones into pomegranate seeds, peel, and juice [14-17]. Still, the lack of pomegranate studies in short and long term with the growing amount of pomegranate consumption confirmed the need to investigate the effects of short and prolonged ingestion in health and disease establish the potential roles that may make pomegranate one of 
the most chosen foods of the future. The aim of this study included on: 1-study the effect of DEN and PB on normal kidney. 2- Study the effect of different pomegranate extract PE, SOE, and PJ on normal kidney for short and long term. 3- Study the chemoprevention of different pomegranate extract $\mathrm{PE}$, SOE, PJ against of DEN and PB for short and long term. The studies focused on the changes levels of DNAF (DAN fragmentation), caspase-3 activity, and kidney function test.

\section{Experimental Procedures}

\subsection{Chemicals}

Caspase-3 assay kit was obtained from BioSource International,Inc. (Camarillo, CA, USA). An AxyPrep DNA gel extraction and purification kit was obtained from Montreal Biotechnologies Inc. (Dorval, PQ, Canada), DEN (Diethylnitrosamine) was purchased from Sigma- Aldrich (St. Louis, MO, USA).

\subsection{Plant}

Pomegranate plant from the family Lythraceae was purchased from the local market. The fruits were peeled mechanically. Then the seeds of the fruit containing the intact juice sacs were manually separated and filtered (PJ), and the filtrate was stored at $4^{\circ} \mathrm{C}$ until used [17] The pomegranate peels were washed well in running water and dried in sun solar system. The dried clean peels were extracted with soaking in $70 \%$ methanol $(1: 6 \mathrm{w} / \mathrm{v})$ for four hours. The methanolic extract was evaporated in rotary evaporator at $40{ }^{\circ} \mathrm{C}$ to obtain a sticky extract, PE (peel extract) (yield: $9 \%$ ) [18, 19]. The pomegranate hard white seeds were washed well in running water and dried in sun solar system. The dried clean seeds were mechanically crushed in crushing machine. Then crushed seeds were extracted with n-hexane (1: $5 \mathrm{w} / \mathrm{v})$. The hexane extract containing seed oil was concentrated in rotary evaporator at $40{ }^{\circ} \mathrm{C}$ to obtain SOE (seed oil extract) (yield: $15 \%$ ).

\subsection{Animals}

160 adult male Sprague-Dawely rats weighing 100-110 g were obtained from faculty of medicine Alexandria University, Egypt. All rats were examined for health status and their room was designed to maintain the temperature at $25{ }^{\circ} \mathrm{C}$, relative humidity at approximately $50 \%$ and $12 \mathrm{~h}$ light/dark photoperiod for 2 weeks prior to handling. The animals were then housed in stainless-steel cages, given standard diet and water throughout the study and observed daily for abnormal signs. After acclimatization, rats were divided into eight groups of twenty rats. All animal experiments were approved by the Ethics Committee of the Experimental Animal Care Society.

Control group (C): untreated rats.

(DEN) group: Rats were injected intraperitoneally, IP, with $200 \mathrm{mg}$ of DEN/kg body mass (bm) as one dose [20] At the beginning of the 2nd week, the animals were given drinking water containing $500 \mathrm{ppm}$ of $\mathrm{PB}$ for 20 weeks [21, 22] (i.e. short term experimental period is 5 weeks $=35$ days and long term experimental period is 22 weeks $=154$ days).

(PE) group: Rats were treated orally (using oral gavages) with a daily dose $250 \mathrm{mg} \mathrm{PE} / \mathrm{kg}$ bm [23] for 22 weeks. (i.e. short term experimental period is 5 weeks $=35$ days and long term experimental period is 22 weeks $=154$ days).

(PE-DEN) group: Rats were treated orally (using oral gavages) with a daily dose $250 \mathrm{mg} \mathrm{PE} / \mathrm{kg}$ bm for 2 weeks. At the beginning of the $3 \mathrm{rd}$ week, rats were treated with DEN (as described previously) in addition to the PE treatment. At the beginning of the fourth week, rats were treated with $\mathrm{PB}$ with continuous intake of PE until the 22 week of the experiment (i.e., Rats were treated with PE pre, during, and post DEN and PB treatment) $[20,23]$ (i.e. short term experimental period is 5 weeks $=35$ days and long term experimental period is 22 weeks $=154$ days).

(SOE) group: Rats were treated orally (using oral gavages) with a daily dose $2 \mathrm{ml} \mathrm{SOE} / \mathrm{kg}$ bm for 22 weeks [24]. (i.e. short term experimental period is 5 

Rat Kidney Induced by Diethylnitrosamine and Phenobarbital

weeks $=35$ days and long term experimental period is 22 weeks $=154$ days $)$.

(SOE-DEN) group: Rats were treated orally (using oral gavages) with a daily dose $2 \mathrm{ml} \mathrm{SOE} / \mathrm{kg}$ bm for 2 weeks. At the beginning of the 3 rd week, rats were treated with DEN (as described previously) in addition to the SOE treatment. At the beginning of the fourth week, rats were treated with $\mathrm{PB}$ with continuous intake of SOE until the 22 week of the experiment (i.e., Rats were treated with SOE pre, during, and post DEN and PB treatment) [20, 24] (i.e. short term experimental period is 5 weeks $=35$ days and long term experimental period is 22 weeks $=154$ days $)$.

(PJ) group: Rats were treated orally (using oral gavages) with a daily dose $1 \mathrm{~mL} \mathrm{PJ} / \mathrm{kg}$ bm for 22 weeks. ) [16] (i.e. short term experimental period is 5 weeks $=35$ days and long term experimental period is 22 weeks $=154$ days $)$.

(PJ-DEN) group: Rats were treated orally (using oral gavages) with a daily dose $1 \mathrm{~mL} \mathrm{PJ} / \mathrm{kg}$ bm for 2 weeks. At the beginning of the $3 \mathrm{rd}$ week, rats were treated with DEN (as described previously) in addition to the PJ treatment. At the beginning of the fourth week, rats were treated with $\mathrm{PB}$ with continuous intake of PJ until the 22 week of the experiment (i.e., Rats were treated with PJ pre, during, and post DEN and PB treatment) $[16,20]$ (i.e. short term experimental period is 5 weeks $=35$ days and long term experimental period is 22 weeks $=154$ days).

At the end of each period of studying (after 35 days or 150 days) of acclimatization, 80 animals were randomly taken from each group in each period to stop feeding for $12 \mathrm{~h}$ prior to killing. Rats were anaesthetized by diethylether and killed. Kidneys were removed immediately, and washed with cold saline solution $(0.9 \% \mathrm{NaCl})$, weighed, divided into two parts and kept at $-80{ }^{\circ} \mathrm{C}$ until used for determination of DNAF (DNA fragmentation) and caspase-3 activity.

Unheparinized blood samples were collected, kept at room temperature for $15 \mathrm{~min}$ and then sera were separated by centrifugation at $3000 \mathrm{rpm}$ at $2{ }^{\circ} \mathrm{C}$ for 20 min. Sera were stored at $-30{ }^{\circ} \mathrm{C}$ until used for the determination of Kidney function test.

\subsection{Biochemical Assay}

\subsubsection{Caspase-3 Assay (EC 3.4.22.56)}

Caspase-3 activity was determined using a colorimetric kit according to the method of [25]kidney tissues were homogenized in four volumes of cold cell lysis buffer $(50 \mathrm{mM}$ Tris- $\mathrm{HCl}$ buffer containing $0.2 \mathrm{M}$ $\mathrm{NaCl}$ and $1 \%$ Triton $\mathrm{X}-100, \mathrm{pH} 6.8$ ) using a Teflon glass homogenizer. The homogenates were centrifuged at $44,720 \mathrm{~g}$ for $3 \mathrm{~min}$ at $4{ }^{\circ} \mathrm{C}$, and the supernatants were kept at $-80{ }^{\circ} \mathrm{C}$. The supernatant $(50 \mu \mathrm{L}=150 \mu \mathrm{g}$ protein) was put in a microplate reader, then $50 \mu \mathrm{L}$ (microliter) reaction buffer and $5 \mu \mathrm{L}$ (microliter) of 4 $\mathrm{mM}$ (millimolar) substrate were added, mixed well, and incubated at $37^{\circ} \mathrm{C}$ in the dark for 2 hours. The reaction rate was determined by measuring the absorbance of the produced yellow color at $405 \mathrm{~nm}$ (nanometer) against a blank using a microplate reader (Bio-Tek Instruments, Bad Friedrichshall, Germany). Fold increase in caspase-3 activity should be determined by direct comparison to the level of the control.

\subsubsection{DNA Fragmentation}

DNAF was determined in the kidney homogenate using agarose gel electrophoresis according to the method of [26]. Kidney tissues were homogenized in $1: 5$ weights per volume $(1: 5 \mathrm{w} / \mathrm{v}) 50$ millimolar $(\mathrm{mM})$ Tris- $\mathrm{HCl}$ buffer containing $20 \%$ sucrose and 50 millimolar (mM) EDTA, pH 7.6. DNA was isolated using a DNA purification kit. Then 15 microgram per lane of DNA (15 $\mu \mathrm{g} /$ lane DNA) was separated by electrophoresis on $1 \%$ agarose gel containing 25 microliter $(\mu \mathrm{L})$ ethidium bromide at five volt per one centiliter $(5 \mathrm{~V} / 1 \mathrm{~cm})$ for 2-3 hours, and visualized under UV light using a multiband transilluminator from Consort (Turnhout, Belgium).

\subsubsection{Kidney Function Test}

Creatinine, urea and uric acid concentrations were determined according to the methods of [27-29]. 


\subsection{Statistical Analysis}

All data are presented as means $(\mathrm{X}) \pm \mathrm{S} . \mathrm{D}$ (standard deviation). Comparisons between the means of various treatment groups were analyzed using LSD (least significant difference) test. Differences were considered significant at $p<0.05$. All statistical analyses were performed using the statistical software SPSS v11.5 (SPSS, Inc., Chicago, IL, USA).

\section{Results}

\subsection{Caspase-3 Activity}

During the first period of study (35 days), caspase-3 levels in control (C) were $0.15 \pm 0.13$ lower than that in DEN group $0.72 \pm 0.12 ; p<0.05$. The enzyme levels in PE, SOE and PJ groups were $0.20 \pm 0.11,0.16 \pm 0.08$ and $0.16 \pm 0.13$ respectively compared to $C ; p<0.05$. The enzyme levels in PE-DEN, SOE-DEN, PJ-DEN groups were $0.25 \pm 0.09,0.21 \pm 0.11$ and $0.25 \pm 0.12$ respectively compared to DEN; $p<0.05$. (Table1). After 154 days of study,caspase-3 levels in control(C) were $0.15 \pm 0.13$ lower than that in DEN group $0.87 \pm$ 0.12; $\mathrm{p}<0.05$.The enzyme levels in PE, SOE and PJ groups were $0.30 \pm 0.08,0.25 \pm 0.13$ and $0.36 \pm 0.06$ respectively compared to $\mathrm{C} ; \mathrm{p}<0.05$. The enzyme levels in PE-DEN, SOE-DEN, PJ-DEN groups were $0.45 \pm 0.11,0.25 \pm 0.09$ and $0.46 \pm 0.08$ respectively compared to DEN; $\mathrm{p}<0.05$. (Table 1)

\subsection{Kidney Function}

During the first period of study (35 days), creatinine, urea and uric acid concentrations were increased significantly after administration of DEN and PB $(1.004 \pm 0.08 \mathrm{mg} / \mathrm{dl}, 46.657 \pm 0.03 \mathrm{~g} / \mathrm{dl}, 3.90 \pm 0.4$ $\mathrm{mg} / \mathrm{dl})$ respectively as compared to the $\mathrm{C}(0.625 \pm 0.12$ $\mathrm{mg} / \mathrm{dl}, 44.157 \pm 0.01 \mathrm{~g} / \mathrm{dl}, 2.10 \pm 0.01 \mathrm{mg} / \mathrm{dl}) ; p<0.05$. Creatinine, urea and uric acid concentrations were $(0.543 \pm 0.14 \mathrm{mg} / \mathrm{dl}, 40.161 \pm 0.09 \mathrm{~g} / \mathrm{dl}, 2.0 \pm 0.22$ $\mathrm{mg} / \mathrm{dl})$ in PE group, $(0.544 \pm 0.09 \mathrm{mg} / \mathrm{dl}, 44.154 \pm 0.03$ $\mathrm{g} / \mathrm{dl}, 1.53 \pm 0.21 \mathrm{mg} / \mathrm{dl})$ in SOE group and $(0.624 \pm$ $0.01 \mathrm{mg} / \mathrm{dl}, 44.091 \pm 0.13 \mathrm{~g} / \mathrm{dl}, 2.1 \pm 0.11 \mathrm{mg} / \mathrm{dl})$ in PJ group compared to $\mathrm{C} ; p<0.05$. Creatinine concentrations in PE-DEN, SOE-DEN and PJ-DEN were $0.736 \pm 0.07 \mathrm{mg} / \mathrm{dl}, 0.548 \pm 0.11 \mathrm{mg} / \mathrm{dl}$ and 0.787 $\pm 0.01 \mathrm{mg} / \mathrm{dl}$ respectively compared to DEN; $p<$ 0.05 .Urea concentrations in PE-DEN, SOE-DEN and PJ-DEN were $(43.900 \pm 0.04 \mathrm{~g} / \mathrm{dl}, 25.500 \pm 0.09 \mathrm{~g} / \mathrm{dl}$, $44.092 \pm 0.12 \mathrm{~g} / \mathrm{dl}$ ) respectively compared to DEN; $p<$ 0.05 . Uric acid concentrations in PE-DEN, SOE-DEN and PJ-DEN were $(2.74 \pm 0.09 \mathrm{mg} / \mathrm{dl}, 2.10 \pm 0.11 \mathrm{mg} / \mathrm{dl}$, $2.10 \pm 0.21 \mathrm{mg} / \mathrm{dl}$, respectively compared to DEN; $p<$ 0.05 (Table 1).

After 154 days of study, creatinine, urea and uric acid concentrations were increased significantly after administration of DEN and PB $(1.544 \pm 0.13 \mathrm{mg} / \mathrm{dl}$, $49.657 \pm 0.07 \mathrm{~g} / \mathrm{dl}, 4.90 \pm 0.14 \mathrm{mg} / \mathrm{dl})$ respectively as compared to the $\mathrm{C}(0.625 \mathrm{a} \pm 0.01 \mathrm{mg} / \mathrm{dl}, 44.157 \mathrm{a} \pm$ $0.08 \mathrm{~g} / \mathrm{dl}, 2.10 \mathrm{a} \pm 0.11 \mathrm{mg} / \mathrm{dl}) ; p<0.05$. Creatinine, urea and uric acid concentrations were $(1.693 \pm 0.12$ $\mathrm{mg} / \mathrm{dl}, 49.101 \pm 0.09 \mathrm{~g} / \mathrm{dl} 2.5 \pm 0.23 \mathrm{mg} / \mathrm{dl})$ in PE group, $(0.504 \pm 0.06 \mathrm{mg} / \mathrm{dl}, 48.154 \pm 0.09 \mathrm{~g} / \mathrm{dl}, 1.55 \pm 0.21$ $\mathrm{mg} / \mathrm{dl})$ in SOE group and $(1.694 \pm 0.11 \mathrm{mg} / \mathrm{dl}, 48.171 \pm$ $0.07 \mathrm{~g} / \mathrm{dl}, 2.51 \pm 0.16 \mathrm{mg} / \mathrm{dl}$ ) in PJ group compared to $\mathrm{C} ; p<0.05$. Creatinine concentrations in PE-DEN, SOE-DEN and PJ-DEN were $0.626 \pm 0.05 \mathrm{mg} / \mathrm{dl}, 0.528$ $\pm 0.11 \mathrm{mg} / \mathrm{dl}$ and $0.702 \pm 0.12 \mathrm{mg} / \mathrm{dl}$ respectively compared to DEN; $p<0.05$. .Urea concentrations in PE-DEN, SOE-DEN and PJ-DEN were $(42.990 \pm$ $0.11 \mathrm{~g} / \mathrm{dl}, 25.500 \mathrm{f} \pm 0.08 \mathrm{~g} / \mathrm{dl}, 43.071 \pm 0.12 \mathrm{~g} / \mathrm{dl})$ respectively compared to DEN; $p<0.05$. Uric acid concentrations in PE-DEN, SOE-DEN and PJ-DEN were $(2.14 \pm 0.19 \mathrm{mg} / \mathrm{dl}, 2.49 \pm 0.21 \mathrm{mg} / \mathrm{dl}, 2.90 \pm 0.15$ $\mathrm{mg} / \mathrm{dl}$, respectively compared to DEN; $p<0.05$ (Table 1). The changeable Percentage in the levels of biochemical parameters between 35 days and 154 days regarding to caspase-3, Creatinine, urea and uric acid has been shown in (Table 2).

\subsection{DNAF (DNA Fragmentation) in Kidney Tissue}

During the first period of study (35 days), the agarose gel electrophoresis showed very low DNAF (DNA laddering) in the kidney tissue of the Control. The 
Table 1 Biochemical parameters of different studied groups.

\begin{tabular}{|c|c|c|c|c|c|c|c|c|}
\hline Particulars(in & $\mathrm{C}$ & DEN & $\mathrm{PE}$ & PE-DEN & SOE & SOE-DEN & PJ & PJ-DENn \\
\hline \multicolumn{9}{|c|}{ Short term study(35 days) } \\
\hline \multicolumn{9}{|l|}{ Tissue } \\
\hline Caspase -3 activity & $0.15^{\mathrm{a}} \pm 0.13$ & $0.72^{b} \pm 0.12$ & $0.20^{\mathrm{c}} \pm 0.11$ & $0.25^{\mathrm{d}} \pm 0.09$ & $0.16^{\mathrm{a}} \pm 0.08$ & $0.21^{\mathrm{e}} \pm 0.11$ & $0.16^{\mathrm{a}} \pm 0.13$ & $0.25^{\mathrm{d}} \pm 0.12$ \\
\hline \multicolumn{9}{|c|}{ Serum } \\
\hline Creatinine (mg/dl) & $0.625^{\mathrm{a}} \pm 0.12$ & $1.004^{\mathrm{b}} \pm 0.08$ & $0.543^{c} \pm 0.14$ & $0.736^{\mathrm{d}} \pm 0.07$ & $0.544^{\mathrm{c}} \pm 0.09$ & $0.548^{\mathrm{c}} \pm 0.11$ & $0.624^{\mathrm{a}} \pm 0.01$ & $0.787^{\mathrm{e}} \pm 0.01$ \\
\hline Urea $(\mathrm{g} / \mathrm{dl})$ & $44.157^{\mathrm{a}} \pm 0.01$ & $46.657^{b} \pm 0.03$ & $40.161^{c} \pm 0.09$ & $43.900^{\mathrm{a}} \pm 0.04$ & $44.154^{\mathrm{a}} \pm 0.03$ & $25.500^{d} \pm 0.09$ & $44.091^{\mathrm{d}} \pm 0.13$ & $44.092^{\mathrm{d}} \pm 0.12$ \\
\hline Uric acid $(\mathrm{mg} / \mathrm{dl})$ & $2.10^{\mathrm{a}} \pm 0.01$ & $3.90^{\mathrm{b}} \pm 0.4$ & $2.0^{\mathrm{a}} \pm 0.22$ & $2.74^{\mathrm{d}} \pm 0.09$ & $1.53^{\mathrm{e}} \pm 0.21$ & $2.10^{\mathrm{a}} \pm 0.11$ & $2.1^{\mathrm{a}} \pm 0.11$ & $2.10^{\mathrm{a}} \pm 0.21$ \\
\hline \multicolumn{9}{|c|}{ Long term study(154 days) } \\
\hline \multicolumn{9}{|l|}{ Tissue } \\
\hline Caspase -3 activity & $0.15^{\mathrm{a}} \pm 0.12$ & $0.87^{b} \pm 0.12$ & $0.30^{\mathrm{c}} \pm 0.08$ & $0.45^{\mathrm{d}} \pm 0.11$ & $0.25^{\mathrm{e}} \pm 0.13$ & $0.25^{\mathrm{e}} \pm 0.09$ & $0.36^{\mathrm{f}} \pm 0.06$ & $0.46^{\mathrm{d}} \pm 0.08$ \\
\hline \multicolumn{9}{|l|}{ Serum } \\
\hline Creatinine (mg/dl) & $0.625^{\mathrm{a}} \pm 0.01$ & $1.544^{\mathrm{b}} \pm 0.13$ & $1.693^{c} \pm 0.12$ & $0.626^{\mathrm{a}} \pm 0.05$ & $0.504^{\mathrm{d}} \pm 0.06$ & $0.528^{\mathrm{e}} \pm 0.11$ & $1.694^{\mathrm{c}} \pm 0.11$ & $0.702^{\mathrm{f}} \pm 0.12$ \\
\hline Urea $(\mathrm{g} / \mathrm{dl})$ & $44.157^{\mathrm{a}} \pm 0.08$ & $49.657^{b} \pm 0.07$ & $49.101^{\mathrm{c}} \pm 0.09$ & $42.990^{\mathrm{d}} \pm 0.11$ & $48.154^{\mathrm{e}} \pm 0.09$ & $25.500^{\mathrm{f}} \pm 0.08$ & $48.171^{\mathrm{e}} \pm 0.07$ & $43.071^{\mathrm{d}} \pm 0.12$ \\
\hline Uric acid (mg/dl) & $2.10^{\mathrm{a}} \pm 0.11$ & $4.90^{b} \pm 0.14$ & $2.5^{c} \pm 0.23$ & $2.14^{\mathrm{d}} \pm 0.19$ & $1.55^{\mathrm{e}} \pm 0.21$ & $2.49^{\mathrm{c}} \pm 0.21$ & $2.51^{\mathrm{c}} \pm 0.16$ & $2.90^{\mathrm{f}} \pm 0.15$ \\
\hline \multicolumn{9}{|c|}{$\begin{array}{l}\text { Group C - control rats; group DEN - rats treated with DEN and PB; PE (peel extract). PE-DEN (rats treated with PE pre, during, and post DEN and PB administration), SOE (seed o } \\
\text { extract), SOE-DEN (rats treated with SOE pre, during, and post DEN and PB administration), PJ (pomegranate juice), PJ-DEN (rats treated with PJ pre, during, and post DEN and P } \\
\text { administration). } \\
\text { Results are given as mean } \pm \text { S.D. for ten rats. Values are expressed as mean } \pm \text { S.D. for ten rats. Within each row, values with different letter are significantly different at p }<0.05 \text {. }\end{array}$} \\
\hline le 2 & & & & & & & & \\
\hline \multicolumn{2}{|c|}{$\%$ of change between $35 \& 1154$ days } & $\mathrm{C}$ & DEN & $\mathrm{PE}$ & SOE & SOE-DEN & $\overline{\mathrm{PJ}}$ & PJ-DEN \\
\hline \multicolumn{2}{|l|}{ Caspase -3 activity } & 0.0 & $\uparrow 20.8$ & $\uparrow 50.0$ & $\uparrow 56.3$ & $\uparrow 19.0$ & $\uparrow 125.0$ & $\uparrow 84.0$ \\
\hline \multicolumn{2}{|l|}{ Creatinine (mg/dl) } & 0.0 & $\uparrow 53.8$ & $\uparrow 211.8$ & $\downarrow 7.4$ & $\downarrow 3.6$ & $\uparrow 171.5$ & $\downarrow 10.8$ \\
\hline \multicolumn{2}{|l|}{ Urea $(\mathrm{g} / \mathrm{dl})$} & 0.0 & $\uparrow 6.4$ & $\uparrow 22.3$ & $\uparrow 9.1$ & 0.0 & $\uparrow 9.3$ & $\downarrow 2.3$ \\
\hline \multicolumn{2}{|l|}{ Uric acid (mg/dl) } & 0.0 & $\uparrow 25.6$ & $\uparrow 25.0$ & $\uparrow 1.3$ & $\uparrow 18.6$ & $\uparrow 19.5$ & $\uparrow 38.1$ \\
\hline
\end{tabular}




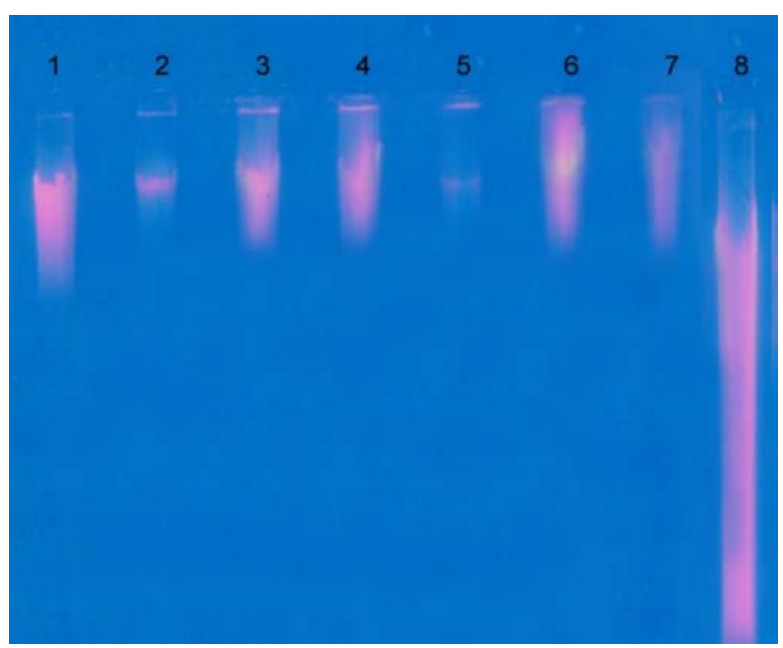

(a)

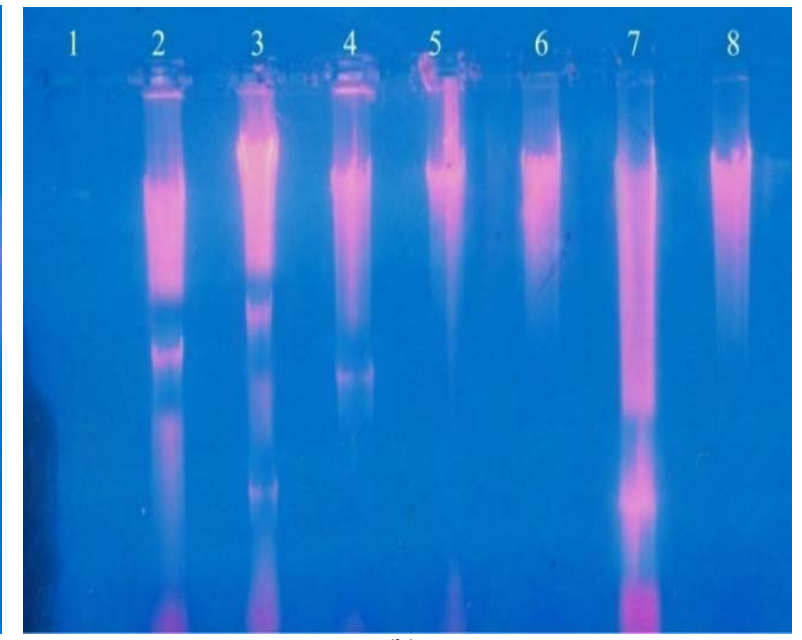

(b)

Fig. 1 DNA fragmentation in all studied groups in kidney tissue.

DNA intact band appears to be condensed near the application point with no DNA smearing suggesting no DNAF. DEN administration and $P B$ resulted in a massive DNAF compared to the $\mathrm{C}$ group. Treatment with PE, SOE, and PJ separately shows no DNA smearing suggesting no DNAF compared to control. Treatment with PE, SOE, PJ pre, during, and post DEN and $\mathrm{PB}$ administration decreased DNAF compared to the DEN group (Fig 1a). After 154 days of study, the agarose gel electrophoresis showed very low or undetectable DNA laddering (DNAF) in the kidney tissue of the Control. DEN administration and PB resulted in a massive DNAF compared to the $\mathrm{C}$ group. Treatment with PE, SOE, and PJ separately shows DNA smearing suggesting a massive DNAF compared to control. Treatment with PE, SOE, PJ pre, during, and post DEN and PB administration decreased DNAF compared to the DEN group (Fig. 1b).

DNA fragmentation separating in $1 \%$ agarose gel electrophoresis and visualized under UV. DNAF in $\mathrm{C}$ (control), DEN (diethyl nitrosamine- Phenobarbital), PE (peel extract). PE-DEN (rats treated with PE pre, during, and post DEN and $\mathrm{PB}$ administration), SOE (seed oil extract), SOE-DEN (rats treated with SOE pre, during, and post DEN and PB administration), PJ (pomegranate juice), PJ-DEN (rats treated with PJ pre, during, and post DEN and PB administration). Fig. 1a.
DNA fragmentation in all studied groups in short 35 days, control (1), PE (2), PE-DEN (3), SOE (4), SOE-DEN (5), PJ (6), PJ-DEN (7), DEN (8). Fig. $1 \mathrm{~b}$. DNA fragmentation in all studied groups in long 154 days, control (1), DEN (2).PE (3), PE-DEN (4), SOE (5), SOE-DEN (6), PJ (7), PJ-DEN (8).

\section{Discussion}

Scientist found that caspase-3 is a major mediator of both apoptotic and necrotic cell death. Increases in both caspase-1 and caspase-3 have been reported in ischemic injury to various organs, including liver, brain, heart and kidney [30]. Both pharmacological inhibitors and genetic trails have been used to inhibit caspases in vivo [31]. The present result has shown a significant elevation in caspase-3 activity and DNAF, creatinine, urea and uric acid levels after DEN and PB administration compared to the control group in both short (35 days) and long term (154 days) of study. This may be due to an enhanced generation and burst of ROS (reactive oxygen species) that accelerated peroxidation of native membrane lipids. Peroxidation of the mitochondrial membrane led to a loss of cell integrity, increase in membrane permeability, and alteration of $\mathrm{Ca}^{2+}$ homeostasis that contribute to cell death and alter kidney function tests [16, 32, 33]. In addition, some ROS interact with various tissue 

Rat Kidney Induced by Diethylnitrosamine and Phenobarbital

compounds leading to dysfunction and injury to the kidney, liver and other organs (and [16, 32]. Elevation in caspase- 3 activities and DNAF after DEN and PB administration indicates that $\mathrm{DEN}$ and $\mathrm{PB}$ caused apoptosis for kidney tissues, and apoptosis is an adaptive process of combating excessive damage. Elevated apoptosis within a diseased kidney should not always be viewed as harmful. The apoptotic process plays a role in the resolution of glomerular inflammation. Failure of these mechanisms might lead to disintegration of neutrophils within the inflamed glomerulus and the development of persistent inflammation leading to scarring [33, 34].

The injury of kidney probably due to the deleterious effect of DEN itself and/or its metabolites which includes ethylcarbonium ions, NO and ROS such as superoxide radicals $\mathrm{O}^{-}$[35]. Ethylcarbonium ions bind to DNA forming adducts and generate superoxide radicals through lipid peroxidation of phospholipid membrane fatty acids [36]. DEN also induces iNOS gene expression and generates NO radicals which react nonenzymatically with $\mathrm{O}^{-}$ forming peroxynitrite $\left(\mathrm{ONOO}^{-}\right.$a reactive nitrogen species) [35]. Furthermore, a continuous administration of PB simultaneous with DEN increases the release of ROS [21]. ROS can attack important biological molecules, such as lipids, proteins, DNA, enzymes, and RNA. Thus, ROS are involved in a number of degenerative diseases such as cancer, cirrhosis, diabetes, and Alzheimer's Disease [37].

Plants, vegetables, fruits and spices used in folk and traditional medicine have been accepted currently as one of the main sources of chemo preventive drug discovery and development [38]. In the present study, the animals treated with PE alone for 35 days showed a slight increase in caspase-3 with non change in DNAF levels and a slight decrease in creatinine, urea and uric acid levels as compared to the controls. These results agree with Settheetham et al, (1995) [39] who found that the administration of aqueous pomegranate $\mathrm{PE}$ results in apoptotic DNA fragmentation and suppression of growth in two human Burkitt's lymphoma cell lines, Raji and P3HR-1. The slight increase in apoptosis in PE group than the control in this study may be due to the effect of tannin which is present in high concentration in PE and acts as proapoptotic. Otherwise, the treatment of rats with $\mathrm{PE}$ alone for 154 days has shown a significant elevation in caspase-3 activity and DNAF, creatinine, urea and uric acid levels compared to the control group, the treatment of rats with PE for a long period led to the accumulation of tannin in the kidney increases its effect and alter kidney function tests. Pervious results reported that tannic acid causes DNA degradation through generation of reactive oxygen species. On the other hand, it exhibits antimutagenic and anticarcinogenic activities, and induces apoptosis in animal cells. It is know that most plant- derived polyphenolic antioxidants also act as pro-oxidants under certain conditions [40]. Other results reported that ellagic acid exhibited both antioxidant activity in V79-4 cells and apoptosis-inducing activity in human osteogenic sarcoma cells through the up-regulation of Bax and activation of caspase-3 [12, 41]. In vitro studies using different cancer cell lines demonstrated that pomegranate juice, seeds, and oil can inhibit cancer cell invasiveness and proliferation, cause cell cycle disruption, induce apoptosis, and inhibit tumor growth [42].

The present result has shown a significant decline in caspase- 3 activity and DNAF, creatinine, urea and uric acid levels in PE-DEN compared to the DEN in studies, 35 days and 154 days, this indicated that PE have selective targeting effects to improve kidney function tests and injuries induced with DEN and PB. The renoprotective efficacy of pomegranate peels; attributed to antioxidant, anti-inflammatory and different signaling pathway mechanisms to their high polyphenolic contents. [43] Shaban et al, (2013), reported that pomegranate extracts $(\mathrm{PE}, \mathrm{SOE})$ reduced liver oxidative stress and apoptosis induced by DEN 
for 23 weeks. Scientists demonstrate that pomegranate peel ethanol extract is a potent nephroprotective agent and suppresses Fe-NTA-induced renal oxidative damage in rats [44]. Ahmed and Zaki, (2009) [45] reported that animals administration of Pomegranate peel extract was significantly attenuated the toxicity and oxidative stress induced by chlorpyrifos-ethyl.

Administration of SOE alone showed that there were slight increases in caspase-3 activity with non change in DNAF levels as well as significant increase in caspase-3 activity, DNAF in short and long term of study respectively. Where in both short and long term studies, there were deceases in creatinine, urea and uric acid levels compared to the control group. These results may be due to effect of some steroid components of pomegranate seed oil and accumulated these competent inside the tissues, where Jin et al, (2006) [46] reported that steroid hormone could induce apoptosis of bone marrow-derived macrophages. The detailed mechanisms behind the apoptosis of macrophages induced by steroid hormone are not clear. Pomegranate seed oil decreased serum creatinine, urea, urine glucose and protein concentrations [47].

Otherwise treatment with SOE pre, during, and post DEN and PB administration showed a significant reduction in the levels of in caspase- 3 activity and DNAF, creatinine, urea and uric acid levels after DEN and PB administration compared with the DEN group, this means that SOE contents inhibited the caspase-3 activity and DNA fragmentation in selective targeting way and this led to reduce apoptosis induced with DEN and improve kidney functions. It has been reported that SOE contents gamma-tocopherol, ursolic acid, 17-alpha-estradiol, estrone, estriol, testosterone, beta-sitosterol, coumesterol, campesterol, stigmasterol and punicic acid acts as antioxidants and anti-apoptotic $[43,48,49]$. Where the anti-apoptotic selective targeting of pomegranate seed oil may be due to the effect of estrogenic components, through modulate intracellular $\mathrm{Ca}^{2+}$, prevent inflammation, reduce caspase- 3 activity as well as DNA fragmentation and subsequently, overall cell death [48]. Otherwise Madsen-Bouterse et al, (2006) [50] reported that the mechanism of glucocorticoid regulation of spontaneous apoptosis and implicate steroid receptor activation and subsequent regulation of Bcl-2 family members. Pomegranate seed oil has a protective effect against hexachlorobutadiene and $\mathrm{HgCl} 2$-induced nephrotoxicity in rats[47, 51].

Administration of PJ alone for 35 days in the present study showed that there was slight change in caspase-3 activity and DNAF, creatinine, urea and uric acid levels compared to the control group. While treatment with PJ alone for a long period 154 days showed increase in caspase- 3 and DNAF, creatinine, urea and uric acid levels compared to the control group, this may be due to accumulation of pomegranate juice active compounds. It has been reported that whole fruit caused an elevation in creatinine level in vivo [52]. Pomegranate and its constituents have been safely consumed by humans for several millennia. Nevertheless, several animal studies and human clinical trials have investigated the toxicity of pomegranate over a long period (16).No adverse side effects have been noted in any of these studies, therefore considering safe to consume the fresh fruit or pomegranate juice in general at harvesting season only. Moreover, the health effect of pomegranate can vary due to geographical region, harvesting, and season, which can alter the fruit composition [53]. In addition, pomegranate juice administration in rats for 37 days has no toxic effect [17, 33, 54].

In both short and long term studies treatment with PJ pre, during, and post DEN and PB administration showed a reduction in the levels of in caspase- 3 activity and DNAF, creatinine, urea and uric acid levels after DEN and PB administration compared with the DEN group, This means that, polyphenolic compounds in PJ play an important selective targeting role in quenching the free radicals resulted from the metabolism of DEN, thereby inhibiting lipid peroxidation and protecting membrane lipids from oxidative damage and in turn prevent apoptosis. Our 
results agree with previous study which confirmed the protective role of pomegranate anthocyanins toward apoptosis [55, 56]. Where [57] Rezk, 2013 found that treatment pomegranate juice ameliorate rat renal damage induced by radiation, and this due to pomegranate polyphenolic components'(delphinidin-3,5-diglucoside,

delphinidin-3-glucoside, cyanidin-3,5-diglucoside, cyanidin-3-glucoside, pelargonidin-3,5-diglucosid, pelargonidin-3-glucoside, ellagitannins gallotannins and condensed tannins (proanthocyanidins).

The antioxidant powers of $\mathrm{PJ}$ are related to their high polyphenolic contents and their variation [58]. The antioxidant effects of phenolic compounds of PJ are more potent than many other antioxidant compounds [58] (such as vitamins), and are able to scavenge ROS and reactive nitrogen species which resulted from DEN and PB metabolism [33, 59]. Punicalagin, one of the ellagitannins, is responsible for more than $50 \%$ of the antioxidant activity of the PJ [41]. In addition, ellagic acid decreases both the total hepatic CYP-450 and CYP2E1 that lead to alteration in the DEN and PB metabolism. Chlorogenic acid, caffeic acid, and some nonpolyphenolic compound in PJ such as serotonin are good inhibitors of the n-nitrosation reaction [33]. So polyphenols may be effective not only in protection against oxidative damage but also in inhibiting the formation of potent mutagenic and carcinogenic n-nitroso compound in vivo [11]. Ahmed et al. (2011) [60] found that PJ has significant effect on some oxidants/antioxidants enzymes of liver and kidney. This renoprotective effect of pomegranate extracts can be attributed to its high phenolic and steroid content and the mechanism of action may be through induction of various antioxidant enzymes and scavenging reactive oxygen species [61].

\section{Conclusion}

DEN and PB induced inflammation, apoptosis and toxicity for kidney tissues.

Treatments with pomegranate extracts (PE, SOE and
PJ) for short period (35 days) have no side effects on the normal kidney.

Treatments with pomegranate extracts (PE, SOE and PJ) for a long period (154 days) have side effects on the normal kidney.

The present study demonstrates that, administration of pomegranate extracts (PE, SOE, $\mathrm{PJ}$ ) before, during and post DEN administration reduced apoptosis induced with DEN and PB in both period of study.

We concluded that the treatment with (SOE) is the best followed by (PJ), then (PE) against kidney injuries induced with (DEN).

The side effects of pomegranate extracts may be due to the long period of its administration, which led to accumulation of phenolic and tannin compounds and increase their effects.

The present study showed that pomegranate extract exerts a significant target protective effect against DEN and PB apoptosis in kidney by augmenting host antioxidant defense mechanisms. This extract is a promising agent for the prevention of chemical induced toxicity.

We recommend separating the compounds of pomegranate which have preventive and positive effects from the pomegranate extracts peel, seeds and juice. These compounds are considered economic sources. Using them in pure way in the treatment many types of disease such as cancers.

\section{Acknowledgment}

The authors thank Mohamed Abd El-Mohsen El-Kersh, The Late Dr. Mohamed Magdi Bader El-Dein and Taymour-Lank M. Farawilla for helping in this work.

\section{References}

[1] Davis, M. A., and Ryan, D. H., (1998) "Review Article Apoptosis in the Kidney." Toxicologic Pathology 26 (6): $810-25$.

[2] Thomas, G. L., Yang, B., Wagner, B. E., Savill, J., and El Nahas, A. M., 1998. "Cellular Apoptosis and Proliferation in Experimental Renal Fibrosis." Nephrol Dial Transplant 13: 2216-26. 
[3] Reh, B. D., and Fajen, J. M. 1996. "Worker Exposures to Nitrosamines in a Rubber Vehicle Sealing Plant.” Am. Ind. Hyg. Assoc. J. 57: 918-23.

[4] Brown, J. L., 1999. "N-Nitrosamines." Occup. Med. 14: 839-48.

[5] Sharma, S. P., 2004. "Nitric Oxide and the Kidney." Indian J. Nephrol 14: 77-84.

[6] Cayir, A., Turan, M. I., and Esin, I. S. 2014. “An Examination of the Effects of Phenobarbital on Thyroid Function Tests in Childhood Epilepsy." HK J. Paediatr (New Series) 19: 71-4.

[7] Kitano, M., Ichihara, T., Matsuda, T., Wanibuchi, H., Tamano, S., Hagiwara, A., Imaoka S, Funae Y, Shirai T, and Fukushima, S., 1998. "Presence of a Threshold for Promoting Effects of Phenobarbital on Diethylnitrosamine-Induced Hepatic Foci in the Rat." Carcinogenesis 19: 1475-80.

[8] Richard, R. M., Lesley, M. F., Karen, S., Nicholas, D. H., Albrecht, buchmann, H. W., and Roland wolf, C., 1988 "Regulation of Phenobarbital-Inducible Cytochrome P-450s in Rat and Mouse Liver Following Dexamethasone Administration and Hypophysectomy." Biochem. J. 254: 789-97.

[9] Grzegorczyk, I., Matkowski, A., and Wysokinska, H., 2007. "Antioxidant Activity of Extracts from in vitro Cultures of Salvia Officinalis L." Food Chem. 104: 536-41.

[10] Ross, I. A., 1999. "Medicinal Plants of the World." New Jersey: Humana Press, Totowa, 273-81.

[11] Gil, M. I., Tomas-Berberan, A., Hess-Pierce, B., Holcroft, D. M., and Kader, A. A. 2000. "Antioxidant Activity of Pomegranate Juice and Its Relationship with Phenolic Composition and Processing." J. Agric. Food Chem. 48: 4581-9.

[12] Seeram, N. P., Adams, L. S., Henning, S. M., Niu, Y., Zhang, Y., Nair, M. G., and Heber, D., 2005. "In vitro Antiproliferative, Apoptotic and Antioxidant Activities of Punicalagin, Ellagic Acid and a Total Pomegranate Tannin Extract Are Enhanced in Combination with Other Polyphenols as Found Inpomegranate Juice." J. Nutr. Biochem. 16: 360-7.

[13] Vroegrijk, I. O. C. M., van Diepen, J. A., van den Berg, S., et al., 2011. "Pomegranate Seed Oil, a Rich Source of Punicic Acid, Prevents Diet-Induced Obesity and Insulin Resistance in Mice." Food and Chemical Toxicology 49 (6): 1426-30.

[14] Monica, V., Raquel, H., Pinyi, L., and Josep, B. R. 2013. "Preventive and Prophylactic Mechanisms of Action of Pomegranate Bioactive Constituents." Evidence-Based Complementary and Alternative Medicine Article ID 789764.

[15] Stowe, C. B., 2011. "The Effects of Pomegranate Juice
Consumption on Blood Pressure and Cardiovascular Health." Complementary Therapies in Clinical Practice 17 (2): 113-5.

[16] Shaban, N. Z., El-Kersh, M. A. R., Bader-Eldin, M. M., Kato, S. A., and Asmaa, F. H. 2014. "Effect of Punica Granatum (Pomegranate) Juice Extract on Healthy Liver and Hepatotoxicity Induced by Diethylnitrosamine and Phenobarbital in Male Rats.” J. Med. Food 17 (3): 339-49.

[17] Cerda, B. S., Albaladejo, C., Martinez, M. D., Sanchez, P., Gascon, F., Tomas-Barberan, F., and Espin, J. C. 2006. "Pomegranate Juice Supplementation in Chronic Obstructive Pulmonary Disease: A 5-week Randomized, Double-Blind, Placebo-Controlled Trail Eur." J. Clin. Nutr. 60: 245-53.

[18] Chidambara-Murthy, K. N., Jayaprakasha, G. K., and Singh, R. P. 2002. "Studies on Antioxidant Activity of Pomegranate (Punica Granatum) Peel Extract Using in vivo Models.” J. Agric. Food Chem. 50 (17): 4791-5.

[19] Kim, N. D., Mehta, R., Yu, W., Neeman, I., Livney, T., Amichay, A. , Poirier D., Nicholls, P., Kirby, A., Jiang, W., Mansel, R., Ramachandran, C., Rabi, T., Kaplan, B. and Lansky, E. 2002. "Chemopreventive and Adjuvant Therapeutic Potential of Pomegranate (Punica Granatum) for Human Breast Cancer." Breast Cancer Res. and Treat. 71: 203-17.

[20] Singh, B. N., Singh, B. R., Sarma, B. K., and Singh. H. B. 2009. "Potential Chemoprevention of N-nitro Sodiethylamine-Induced Hepatocarcinogenesis by Polyphenolics from Acacia Nilotica Bark." Chemico-Biological Interactions 181: 20-8.

[21] Katayama, M., Sugie, S., Yoshimi, N., Yamada, Y., Sakata, K., Qiao, Z., Iwasaki, T., Kobayashi, H., and Mori, H. 2003. "Preventive Effect of Fermented Brown Rice and Rice Bran on Diethylnitrosoamine and Phenobarbital, Induced Hepatocarcinogensis in Male F344 Rats." Oncology Reports 10: 875-80.

[22] Siraki, A. G., and O'Brien, P. J. 2002. "Prooxidant Activity of Free Radicals Derived from Phenol-Containing Neurotransmitters." Toxicology 177: 81-90.

[23] Ajaikumar, K. B., Asheef, M., Babu, B. H., and Padikkala, J. 2005. "The Inhibition of Gastric Mucosal Injury by Punicagranatum L (Pome Granate) Methanolic Extract." J. Ethopharmacol. 96: 171-6.

[24] Kohno, H., Suzuki, R., Yasui, Y., Hosokawa, M., Miyashita, K., and Tanaka, T. 2004. "Pomegranate Seed Oil in Conjugated Linolenic Acid Suppresses Chemically Induced Colon Carcinogenesis in Rats." Cancer Sci. 95 (6): 481-6.

[25] Talanian, R. V., Quinlan, C., Trautz, S., Hackett, M. C., Hackett, J. A., Banach, D., Ghayur, T., Brady, K. D., and Wong, W. W. 1997. "Substrate Specificities of Caspase Family Proteases.” J. Biol. Chem. 272: 9677-82. 

Rat Kidney Induced by Diethylnitrosamine and Phenobarbital

[26] Li, X., Fu, G. F., Fan, Y. R., Shi, C. F., Liu, X. J., Xu, G. X., and Wang, J. J. 2003. "Potent Inhibition of Angiogenesis and Liver Tumor Growth by Administration of an Aerosol Containing a Transferrin-Liposome Endostatin Complex." World J. Gastroenterol 9: 262-6.

[27] Barham, D., and Trinder, P. 1972. "An Improved Colour Reagent for the Determination of Blood Glucose by Oxidase System.” Analyst 97: 142 -5.

[28] Bowers, L. D., and Wong, E. T. 1980. "Kinetic Serum Creatinine Assay: A Critical Evaluation and Review." Clin. Chem. 26: 555-61.

[29] Rock, R. C., Walker, W. G., and Jennings, D. 1986. "Nitrogen Intermediates and Renal Function." In: Tie TZ (ed). Text Book of Clinical Chemistry. Pheladelphia: WB Saunders Co. 622-9.

[30] Schulte-Herman, R., Bursch, W., and Marian, B. 1999. "Active Cell Death Apoptosis and Cellular Proliferation as Indicators of Exposure to Carcinogens." IARC Scientific Publications (lyon). 146: 273-85.

[31] Faubel, S., and Edelstein, C. L., 2005. "Caspases as Drug Targets in Ischemic Organ Injury." Curr. Drug Targets Immune Gndoer Metabol Disord 5 (3): 269-87.

[32] Shaban, N. Z., Helmy, M. H., El-Kersh, M. A.R., and Mahmoud, B. F. 2003 "Effects of Bacillius Thuringiensis Toxin on Hepatic Lipid Peroxidation and Free-Radical Scavengers in Rats Given Alpha-Tocopherol or Acetylsalicylate." Comp Biochem Physiol C 135: 405-14.

[33] Hamouda, A. F., Shabana, N. Z., and Talaata, I. M. 2015. "Effects of Some Pyrimidine Derivatives and Pomegranate Juice on Male Rat kidney Injuries Induced by Diethylnitrosamine and Carbon tetrachloride." (BCR2015042201) Biological and Chemical Research 215

[34] yang, B., Johnson, T. S., Thomas, G. I., Watson, P. F., Wagner, B., and El nahas, A. M. 2001. "Apoptosis and Caspase-3 in Experimental Anti-glomerular Basement Membrane Nephritis." J. am soc nephrol 12: 485-95.

[35] Bishayee, A., Barnes, K. F., Bhatia, D., et al. 2010. "Resveratrol Suppresses Oxidative Stress and Inflammatory Response in Diethylnitrosamine-Initiated Rat Hepatocarcinogenesis.” Cancer Prev Res. 3: 753-63.

[36] Marnett, L. J. 2002. "Oxy Radicals, Lipid Peroxidation and DNA Damage.” Toxicology 181 (2): 219-22.

[37] Halliwell, B. and Gutteridge, J. M. C. 1986. "Iron and Free Radicals: Two Aspects of Antioxidant Protection." Trends Biochem. Sci. 11: 372-5.

[38] Aruoma, O. I. 2003. "Methodological Considerations for Characterizing Potential Antioxidant Actions of Bioactive Components in Plant Foods." Mutation Research (523-524): 9-20.

[39] Settheetham, W., and Ishida, T. 1995. "Study of Genotoxic Effect of Antidiarrheal Medicinal Herbs on
Human Cell in vitro." Southeast Asian J. Trap Med. Public Health 1: 306-10.

[40] Khan, N. S., Ahmad, A., and Hadi, S. M. 2000. "Anti-oxidant, Pro-oidant Properties of Tannic Acid and Its Binding to DNA." Chemico-Biological Interaction 125: 177-89.

[41] Han, D. H., Lee, M. J. and Kim, J. H. 2006. "Antioxidant and Apoptosis-Inducing Activities of Ellagic Acid." Anticancer Res. 26: 3601-6.

[42] Albrecht, M., Jiang, W., Kumi-Diaka, J., et al. 2004. "Pomegranate Extracts Potently Suppress Proliferation, Xenograft Growth, and Invasion of Human Prostate Cancer Cells," Journal of Medicinal Food 7 (3): 274-83.

[43] Shaban, N. Z., El-Kersh, M. A., El-Rashidy, F. H., and Habashy, N. H. 2013. "Protective Role of Punica Granatum (Pomegranate) Peel and Seed Oil Extracts on Diethylnitrosamine and Phenobarbital-Induced Hepatic Injury in Male Rats.” Food Chem. 141 (3): 1587-96.

[44] Ahmed, M. M., and ALI, S. E. 2010. "Protective Effect of Pomegranate Peel Ethanol Extract against Ferric Nitrilotriacetate Induced Renal Oxidative Damage in Rats." Journal of Cell and Molecular Biology 7 (2) and 8 (1): 35-43.

[45] Ahmed, M. M., and Zaki, N. I. 2009. "Assessment the Ameliorative Effect of Pomegranate and Rutin on Chlorpyrifos-ethyl-Induced Oxidative Stress in Rats." Nature and Science 7 (10): 49-61.

[46] Jin, L., Ai, X., Liu, L., Wang, Z., Cheng, Y., and Qiao, Z. 2006. "Testosterone Induces Apoptosis via Fas/FasL -Dependent Pathway in Bone Marrow-Derived Macrophages." Methods Find Exp. Clin. Phrmacol. 28 (5) : 283-93

[47] Boroushaki, M. T., Mollazadeh, H., Rajabian, A., Dolati, K., Hoseini, A., Paseban, M., and Farzadnia, M. 2014. "Protective Effect of Pomegranate Seed Oil against Mercuric Chloride-Induced Nephrotoxicity in Rat." Ren Fail, Early Online: 1-6 Informa Healthcare USA, Inc.

[48] Rau, S. W., Dubal, D. B., Böttner, M., Gerhold, L. M., and Wise, P. M. 2003. "Estradiol Attenuates Programmed Cell Death after Stroke-Like Injury." The Journal of Neuroscience 23 (36): 11420-6.

[49] Lansky, E. P., and Newman, R. A. 2007. "Punica Granatum (Pomegranate) and Its Potential for the Prevention and Treatment of Cancer and Inflammation." $J$. Ethnopharmacol 109: 177-206.

[50] Madsen-Bouterse, S. A., Rosa, G. J., and Burton, J. L. 2006. "Glucocorticoid Modulation of BCl-2 Family Members A1 and bak during Delayed Spontaneous Apoptosis of Bovine Blood Neutrophils." Endocrinology 147 (8): 3826-34.

[51] Bouroshaki, M. T., Sadeghnia, H. R., Banihasan, M., and Yavari, S. 2010. "Protective Effect of Pomegranate Seed 
Oil on Hexachlorobutadiene-Induced Nephrotoxicity in Rat Kidneys." Ren Fail 32 (5): 612-7.

[52] Vidal, A., Fallarero, A., Pena, B. R., Medina, M. E., Gra, B., Rivera, F., Gutierrez, Y., and Vuorela, P. M. 2003 "Studies on the Toxicity of Punica Granatum L. (Punicaceae) Whole Fruit Extracts." Journal of Ethnopharmacology 89: 295-300.

[53] Mirdehghan, S. H. and Rahemi, M. 2007. "Seasonal Changes of Mineral Nutrients and Phenolics in Pomegranate (Punica granatum L.) Fruit." Scientia Horticulturae 111 (2): 120-7.

[54] Cerda, B., Ceron, J. J., Tomas, and Barberan, F. A. 2003. "Repeated Oral Administration of High Doses of the Pomegranate Ellagitannin Punicalagin to Rats for 37 Days Is Not Toxic." J. Agric. Food Chem. 51 (11): 3493-501.

[55] Lazze', M. C., Pizzale, R., Savio, M., Stivala, L. A., Prosperi, E., and Bianchi, L. 2003. “Anthocyanins Protect against DNA Damage Induced by Tertiary-Butyl Hydroperoxid in Rat Smooth Muscle and Hepatoma Cells." Muscle Res. 535: 103-15.

[56] Rahman, I., Biswas, S. K., and Kirkham, P. A. 2006 "Regulation of Inflammation and Redox Signaling by
Dietary Polyphenols." Biochem. Pharmacol. 72: 1439-52.

[57] Rezk, R. G. 2013. "Protective Effect of Pomegranate Juice against Radiation-Induced Histological and Ultra Structural Changes in Kidney of Male Albino Rats." Arab Journal of $N$ uclear Science and Applications 46 (4): 300-11.

[58] Ricci, D., Giamperi, L., Bucchini, A., and Fraternale, D. 2006. "Antioxidant Activity of Punica granatum Fruits." Fitoterapia 77: 310-2.

[59] Ahn, D., Putt, D., Kresty, L., Stoner, G. D., Fromm, D., and Hollenberg, P. F.1996. "The Effects of Dietary Ellagic Acid on Rat Hepatic and Esophageal Mucosal Cytochromes P450 and Phase II Enzymes." Carcinogenesis 17: 821-8.

[60] Ahmed, E. A. M., Mohamed, A. D., and Saleh, Al-Q. 2011. "Studies on the Effect of Pomegranate (Punica Granatum) Juice and Peel on Liver and Kidney in Adult Male Rats." Journal of Medicinal Plants Research 5 (20): 5083-8, 30.

[61] El-Sayed, M., and El-Habibi. 2013 "Renoprotective Effects of Punica Granatum (Pomegranate) against Adenine-Induced Chronic Renal Failure in Male Rats." Life Science Journal 10 (4). 